\title{
Enhanced Corrosion Resistance of Recycled Aluminum Alloy 6061 Chips Using Hot Extrusion Followed by ECAP
}

\author{
Mohamed A. Taha $\mathbb{D}^{1},{ }^{1}$ Adel T. Abbas $\mathbb{D}^{2},{ }^{2}$ Faycal Benyahia, ${ }^{2}$ Hamad F. Alharbi $\mathbb{D}^{2}{ }^{2}$ \\ B. Guitián, ${ }^{3}$ and X. Ramón Nóvoa $\mathbb{D}^{3}$ \\ ${ }^{1}$ Department of Mechanical Design and Production, Faculty of Engineering, Zagazig University, Zagazig 44519, Egypt \\ ${ }^{2}$ Department of Mechanical Engineering, College of Engineering, King Saud University, P.O. Box 800, \\ Riyadh 11421, Saudi Arabia \\ ${ }^{3}$ University of Vigo, School of Industrial Engineering (EEI), Campus Universitario, 36310 Vigo, Spain
}

Correspondence should be addressed to Adel T. Abbas; aabbas@ksu.edu.sa

Received 8 April 2019; Accepted 5 September 2019; Published 24 September 2019

Academic Editor: Sylvain Franger

Copyright (c) 2019 Mohamed A. Taha et al. This is an open access article distributed under the Creative Commons Attribution License, which permits unrestricted use, distribution, and reproduction in any medium, provided the original work is properly cited.

\begin{abstract}
The oxidation of aluminum machining chips retards the successful recycling through the conventional remelting route. A promising approach to overthrow this problem is the utilization of solid state recycling in converting aluminum machining chips directly into semifinished products to eliminate the cost of the remelting process and reduce $\mathrm{CO}_{2}$ emissions. Therefore, in recent work, chips of aluminum alloy (AA6061) were recycled by compaction and then extrusion conducted at $500^{\circ} \mathrm{C}$, followed by equal channel pressing (ECAP) to study the resultant material properties and its microstructure. Moreover, the present investigation explores the influence of ECAP after hot extrusion on the corrosive behaviour of the recycled samples in saline solution ( $\mathrm{NaCl})$ by electrochemical impedance spectroscopy (EIS) and linear polarization (LP). The results demonstrated a remarkable enhancement of the recycled chips' properties subjected to hot extrusion followed by the ECAP process. Furthermore, the successive ECAP passes leads to increased film thickness and decreased corrosion rate.
\end{abstract}

\section{Introduction}

Conventional recycling of aluminum scrap through remelting is always accompanied with high energy consumption and material losses up to $20 \%$ due to the intensive oxidation of the molten metal [1]. Notably, when dealing with the increase in aluminum machining chips, the losses increased to 50\% due to the great surface area to volume ratio [2]. Consequently, solid state recycling through hot extrusion, patented by Stern [3], was implemented to transform aluminum machining chips into semifinished products excluding the undesirable remelting process. Solid state recycling has many advantages over the conventional recycling, for instance, reduced energy consumption up to $5 \%$, lower cost, and few processing steps [4]. Thereafter, many researchers explored the possibility of solid state recycling through different techniques such as extrusion at elevated temperature [5-11].
Gronostajski et al. [12] applied hot extrusion in the production of composite materials based on $\mathrm{Al}$ alloy machining chips and tungsten powder. The results confirmed the dependency of the extruded chips' mechanical properties on the connection quality between individual chips. Furthermore, Kondoh et al. [13] used repetitively cold extrusion followed by hot forging at $450^{\circ} \mathrm{C}$ to produce cylindrical samples with a diameter of $35 \mathrm{~mm}$. Nevertheless, the long duration of the process was a significant limitation to be applied in industrial applications. Fogagnolo et al. [14] studied solid-state recycled AA6061 chips by both cold and hot compactions with a subsequent hot extrusion. They approved that the processing route including cold compaction followed by hot extrusion is the optimum in terms of saving energy consumption and time. Hence, Tekkaya et al. [4] studied the influence of level of extrusion on the mechanical characteristics of solid-state recycled aluminum 
AA-6060 chips mixed with silicon carbide ( $\mathrm{SiC}$ ) particles by cold compaction followed by the hot extrusion process, as recommended in the previous work. The compacted billets were hot extruded under extrusion ratio and temperature of $34.2^{\circ} \mathrm{C}$ and $500^{\circ} \mathrm{C}$, respectively. The yield strength of the extruded chips was about more than $85 \%$ of that of the asreceived billets extruded under the same conditions [4]. During solid state recycling by hot extrusion, an amount of plastic strain level must be attained to break the surface oxide layers of the chips and achieve a fresh metal surface leading to good bonding [15]. This amount of plastic strain is determined by the extrusion ratio [16]. In order to achieve sound bonding, at least extrusion ratio higher than 25 should be used during the hot extrusion process [13]. Accordingly, the mechanical properties of chip-based profiles are comparable to the mechanical properties of cast materials extruded with the same parameters [17]. However, the downside of using high extrusion ratio for chip extrusion is the narrow size of the cross section of the products for a specific size of the extrusion press. Severe plastic deformation (SPD) techniques impose notably high plastic strain that are capable of refining bulk materials with coarse grain structures. Thereby, in order to increase the level of plastic strain and improve the mechanical properties of the extruded recycled samples, SPD techniques should be combined with the hot extrusion process. Recently, several studies on solid state recycling of machining chips through severe plastic deformation such as ECAP and HPT have been conducted [18-20].

Among the various SPD procedures, equal channel angular pressing (ECAP) is the most auspicious one, as it allows a high strain to be repeatedly imposed into the specimen without significant changes in the cross-sectional dimensions [21]. McDonald et al. [22] used ECAP at $590^{\circ} \mathrm{C}$ for solid state recycling of Ti-6Al-4V machining chips. They favorably produced a fully dense and sound-bonded asrecycled material. However, the presence of chip boundaries covered by oxides decreased the ductility during the tensile test. Hence, a successive annealing heat treatment was conducted to remove the oxide layers. As the process of hot extrusion proved its capability of recycling machining chips without residual porosity [23], Haase et al. [5] investigated the feasibility of hot extrusion integrated with ECAP in one die. The results revealed the exceptional mechanical properties of the chips extruded through the integrated die compared to those of chips extruded through the conventional flat-face extrusion die.

In the reported state of the art, two main lacks are observed: (a) ECAP at room temperature is more efficient in producing high strength materials due to the finer microstructure and lower energy consumption as compared to the same process at a higher temperature; however, almost no one, according to the authors knowledge, has considered the combination of hot extrusion followed by ECAP at room temperature. (b) Moreover, very few works have explored the corrosion behavior of solid-state recycled samples, a piece of information essential for the serviceability of the material. Thus, the present work aims at investigating the feasibility of solid state recycling through cold compaction and hot extrusion followed by ECAP at room temperature and, moreover, exploring the influence of the hot extrusion process and ECAP number of passes on the microstructure development, mechanical properties, and corrosion performance of the as-recycled samples.

\section{Materials and Methods}

The experimental material used in this work is aluminum alloy AA6061 (as-received) whose chemical composition is shown in Table 1. Moreover, the layout for the experimental work is shown in Figure 1. The used chips were machined through dry turning the as-received bar according to the following cutting parameters: cutting speed, $88 \mathrm{~m} / \mathrm{min}$; depth of cut, $1 \mathrm{~mm}$; and feed, $1 \mathrm{~mm} / \mathrm{rev}$. The chips were compacted at room temperature and then extrusion at $500^{\circ} \mathrm{C}$ through the flat-face die with an extrusion ratio of 5.2. After that, the extruded samples were processed up to six passes at room temperature, using an ECAP die channeled at an angle (Ф) equal to $90^{\circ}$, targeting an improvement of their mechanical properties.

Vickers microhardness was conducted under a load of $100 \mathrm{~g}$ applied for 15 seconds at room temperature using a Buehler MicroMet 5100 device. In addition, room temperature tensile tests were performed at an initial strain rate of $8.33 \times 10^{-4} \cdot \mathrm{s}^{-1}$ using the LR300K $(300 \mathrm{kN})$ universal testing machine. The tensile test samples were cut in the extrusion and ECAP direction according to ASTM-B557-06. Relative densities of the as-received and solid-state recycled samples were measured using the Archimedes immersion principle (in distilled water). The microstructure study was conducted on ground and polished samples, etched using Keller's reagent. Zeiss Axio Imager optical microscope was used to investigate the microstructure of the samples made of the original material (as-received) and that after hot extrusion. Moreover, a FEI INSPECT S50 scanning electron microscope (SEM) was used to inspect the microstructure post-ECAP process because of the expected finer microstructure.

For the corrosion test, cylindrical-shaped samples in recycled solid state were used, as shown in Table 2. The samples were introduced in a saline solution at a temperature of $20 \pm 2^{\circ} \mathrm{C}$ to study their electrochemical behaviour using electrochemical impedance spectroscopy (EIS) followed by linear polarization (LP). The samples were coated using cataphoretic coating to control the area exposed to the saline solution. Prior testing, the samples' surface was renewed with 2000 grit $\mathrm{SiC}$ paper and further cleaned with ethanol and water. The corrosion tests were conducted in a standard 3-electrode cell configuration using a large area graphite sheet as the counter electrode, a saturated calomel electrode (SCE) as the reference electrode, and the aluminum sample under test was the working electrode. All the potentials in this report are referred to the SCE electrode. The electrolytic solution was a $0.5 \mathrm{~mol} / \mathrm{l}^{-1} \mathrm{NaCl}$, prepared from deionized water $(\rho>18 \mathrm{M} \Omega \mathrm{cm})$, and analytical grade $\mathrm{NaCl}$ salt. As electrochemical instrumentation, an Autolab PGSTAT 30 with FRA module was employed. The EIS measurements were performed in the $10 \mathrm{kHz}$ to $1 \mathrm{~Hz}$ 
TABLe 1: Chemical composition of aluminum alloy AA6061.

\begin{tabular}{lcccccc}
\hline $\mathrm{Si}$ & $\mathrm{Mg}$ & $\mathrm{Fe}$ & $\mathrm{Cu}$ & $\mathrm{Mn}$ & Others & Al \\
\hline 0.8 & 0.85 & 0.48 & 0.26 & 0.051 & 0.329 & Balance \\
\hline
\end{tabular}

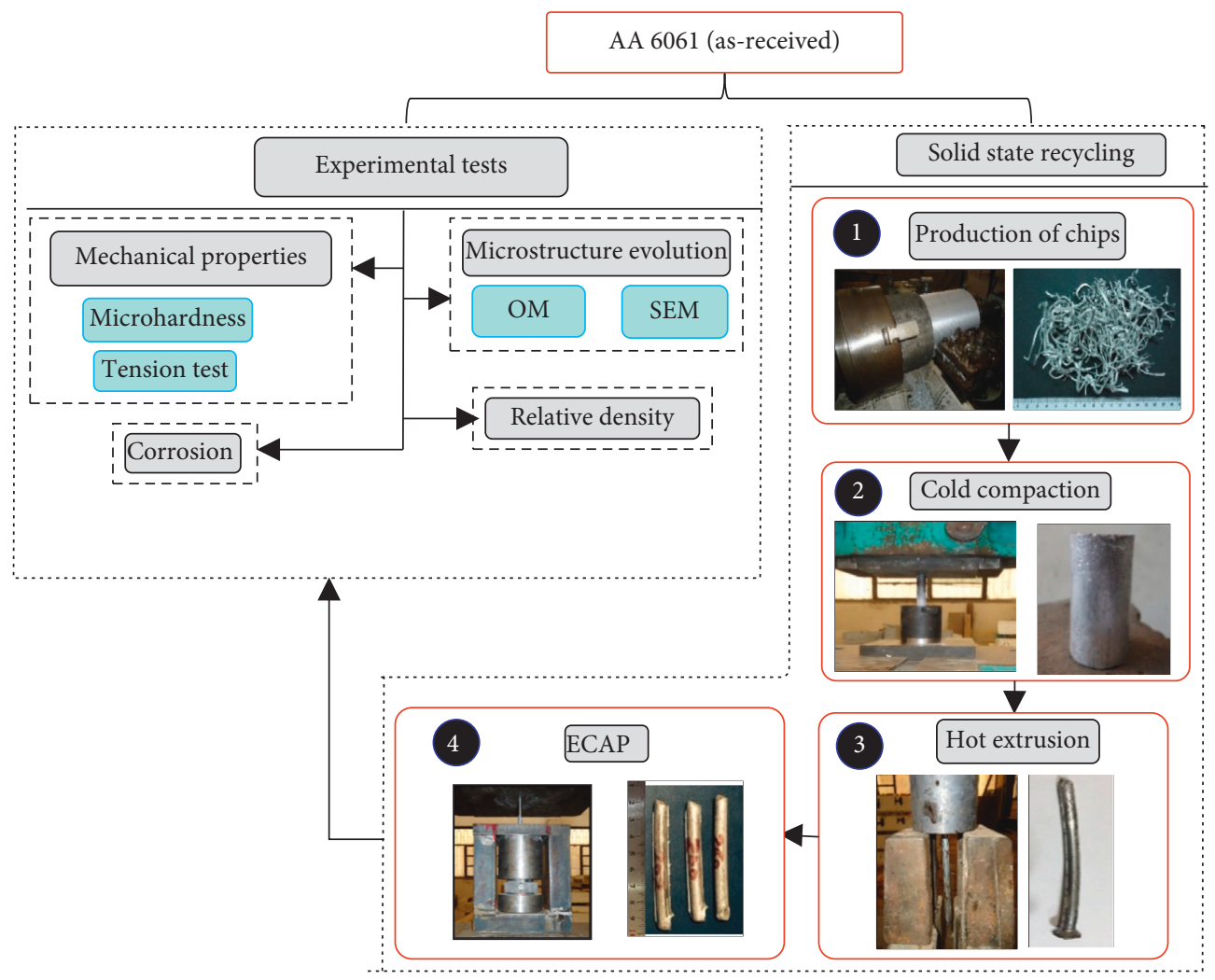

FIGURE 1: Experimental work layout.

TABLE 2: Identification and geometry of the samples used in the corrosion test.

\begin{tabular}{lccc}
\hline & Condition & Diameter $(\mathrm{mm})$ & Active surface $(\mathrm{cross}$ section $)\left(\mathrm{cm}^{2}\right)$ \\
\hline$E 0$ & As-received & 5 & 0.20 \\
$E 1$ & Hot extruded at $500^{\circ} \mathrm{C}$ & 7 & 0.39 \\
$E 2$ & ECAP-2 passes & 7 & 0.39 \\
$E 3$ & ECAP-4 passes & 8 & 0.50 \\
$E 4$ & ECAP-6 passes & 7 & 0.39 \\
\hline
\end{tabular}

frequency window. The frequency was swept from the high to the low frequency limits using seven frequency points per decade. The amplitude of the sinusoidal wave was $10 \mathrm{mV}$ rms. The LP tests were conducted from $-200 \mathrm{mV}$ to $+200 \mathrm{mV}$ vs the open circuit potential (OCP) at $1 \mathrm{mV} \cdot \mathrm{s}^{-1}$ scan rate. These tests were conducted after the EIS tests because they are considered as destructive.

\section{Results and Discussion}

3.1. Microstructure Evolution. Figures 2 and 3 show the samples' microstructure and grain size, respectively. Originally, the microstructure of the first specimen consists of very coarse-grain structure with a grain size of approximately
$48 \mu \mathrm{m}$, as shown in Figure 2(a). On the contrary, the microstructure of the extruded specimen at $500^{\circ} \mathrm{C}$ consists of smaller grain sizes of about $15.9 \mu \mathrm{m}$ grain size, as shown in Figure 3 . The finer grained microstructure can be explained by the intense plastic deformation executed during the machining, hot extrusion, and ECAP processes, as well as chip boundaries that act as obstacles between grains to constrain grain growth $[5,7,24]$. The grain size reduction is in concordance with the previous work presented by Haase et al. [5], and the grain size of AA-6060 recycled samples extruded at 450 and $550^{\circ} \mathrm{C}$ was smaller than the as-received alloy. Moreover, in the previous work by $\mathrm{Hu}$ et al. [7], the original sample's grain size was $200 \mu \mathrm{m}$, while 22,25 , and $11 \mu \mathrm{m}$ were reached for different sizes of $\mathrm{Mg}$ chips recycled through hot 


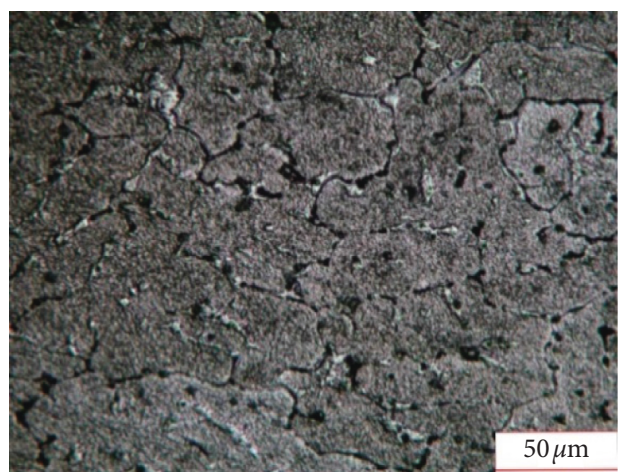

(a)

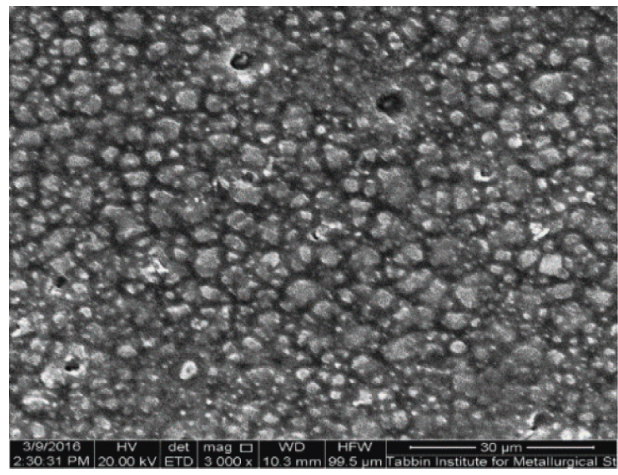

(c)

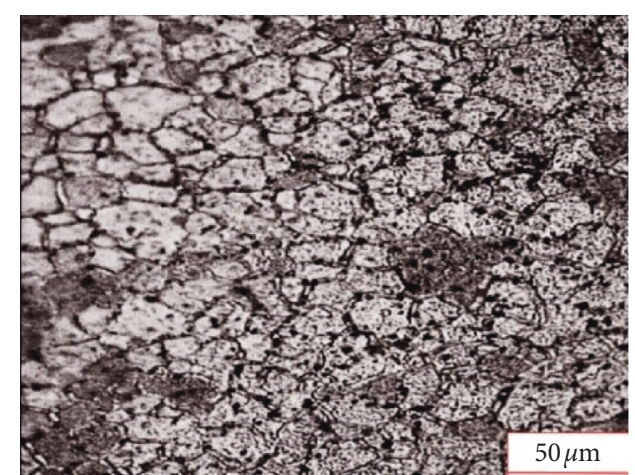

(b)

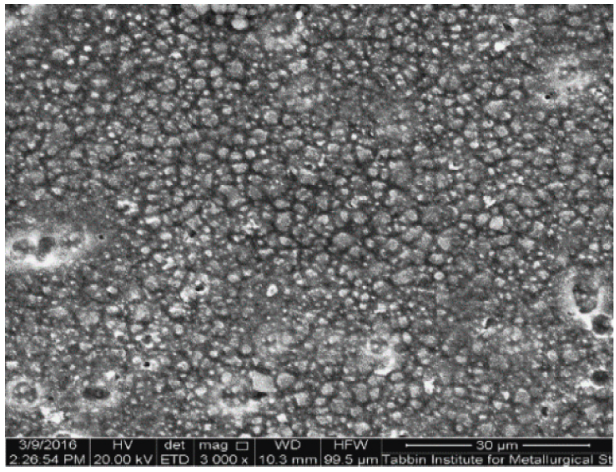

(d)

Figure 2: Microstructure of (a) as-received, (b) extrusion temperature (ET) $=500^{\circ} \mathrm{C}$, (c) ECAP-2 passes, and (d) ECAP-6 passes.

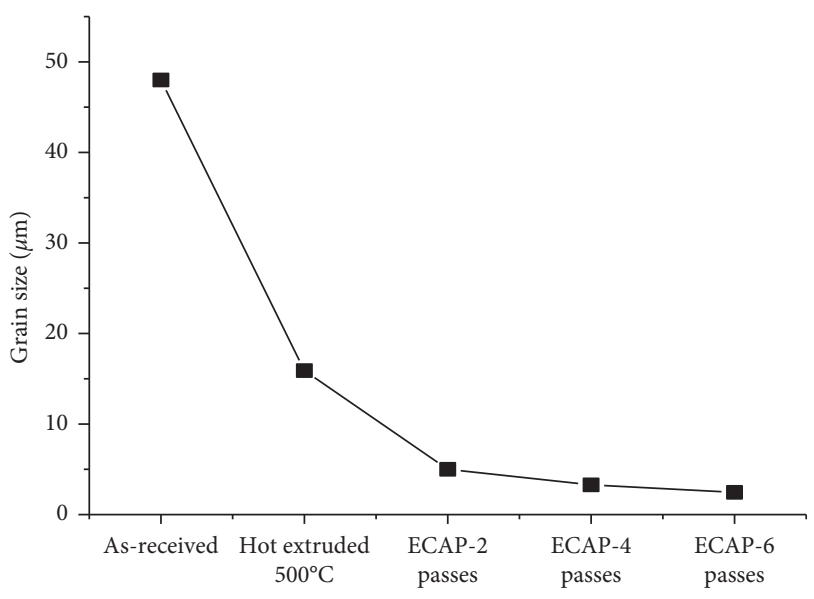

Figure 3: Grain size measurements.

extrusion. SEM micrographs of samples that had undergone ECAP after 2 and 6 passes are shown in Figures 2(c) and 2(d), respectively, and in Figure 4. The incremental grain refinement with increasing numbers of ECAP passes is evident. ECAP sample grain sizes processed after 2, 4, and 6 passes were $5,3.28$, and $2.46 \mu \mathrm{m}$, respectively.

Table 3 shows some mechanical properties related to the recycled aluminum chips such as relative density, ultimate tensile strength, and the microhardness following the hot extrusion succeeded by ECAP processing after 2, 4, and 6 passes. The obtained values, provided in Table 4, for the properties of the solid-state recycled billets show the success of the recycling of those chips into consolidated bulk materials via the proposed procedure of compaction, followed by extrusion at elevated temperature, and ultimately ECAP. Microhardness has increased from $41 \mathrm{HV}$ after extrusion to around $110 \mathrm{HV}$ for an extrusion coupled with ECAP at 6 passes. Similar interpretation for the improvement of the ultimate tensile strength from $132 \mathrm{MPa}$ to about $400 \mathrm{MPa}$ can be drawn. The drastic increase in the mechanical strength is explained by the high dislocation density added to the grain refinement induced by the large deformation caused by the ECAP. Room temperature ECAP deformation also improved relative to the density.

\subsection{Corrosion Behavior}

3.2.1. LP Results. Although LP is the last technique in the testing protocol, it will be treated first to allow for a broad overview of the process under study. Figure 4(a) clearly shows that all the samples corrode under cathodic control and the zero-current potential (close to the corrosion potential) approaches the pitting potential (fast current increase at potentials above $\sim-750 \mathrm{mV}$ ). The enlarged area shown in Figure 4(b) reveals that all the $E_{\text {corr }}$ values allocate in a small window of about $15 \mathrm{mV}$, which anticipates small differences in the electrochemical behaviour.

Roughly, the data in the $\pm 100 \mathrm{mV}$ vicinity of the corresponding $E_{\text {corr }}$ were employed. 


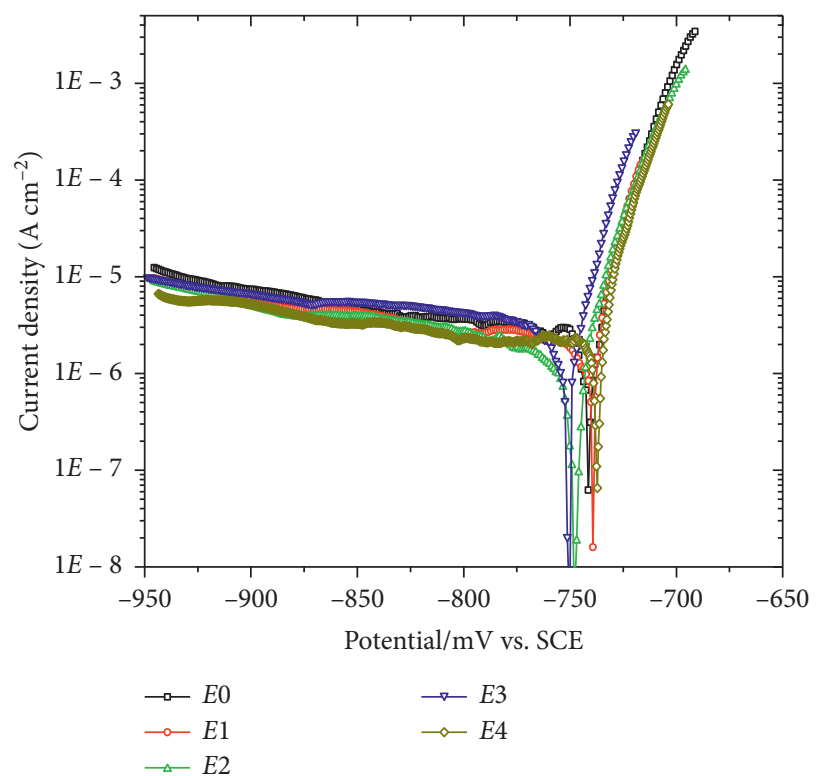

(a)

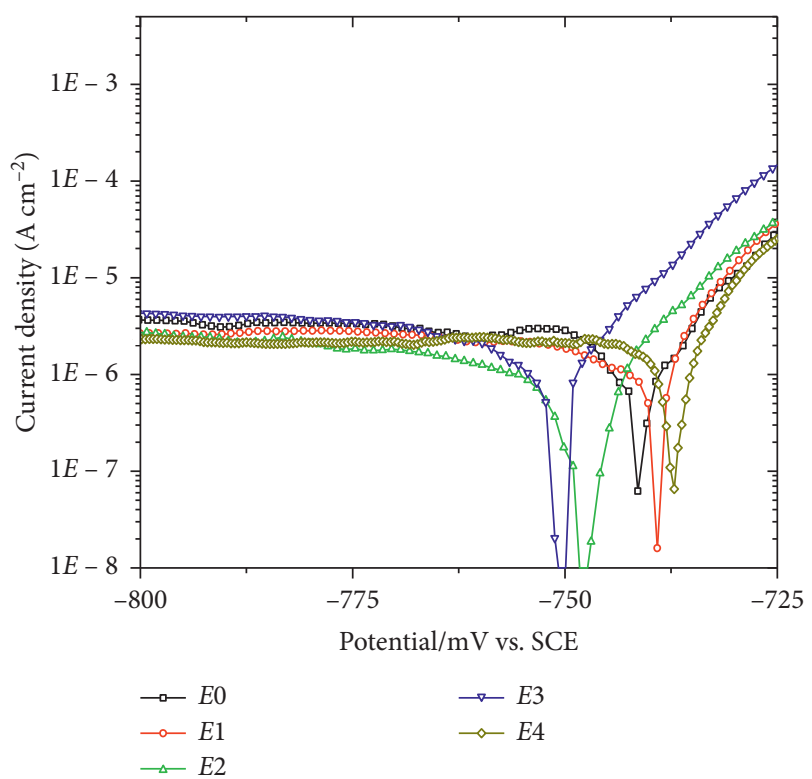

(b)

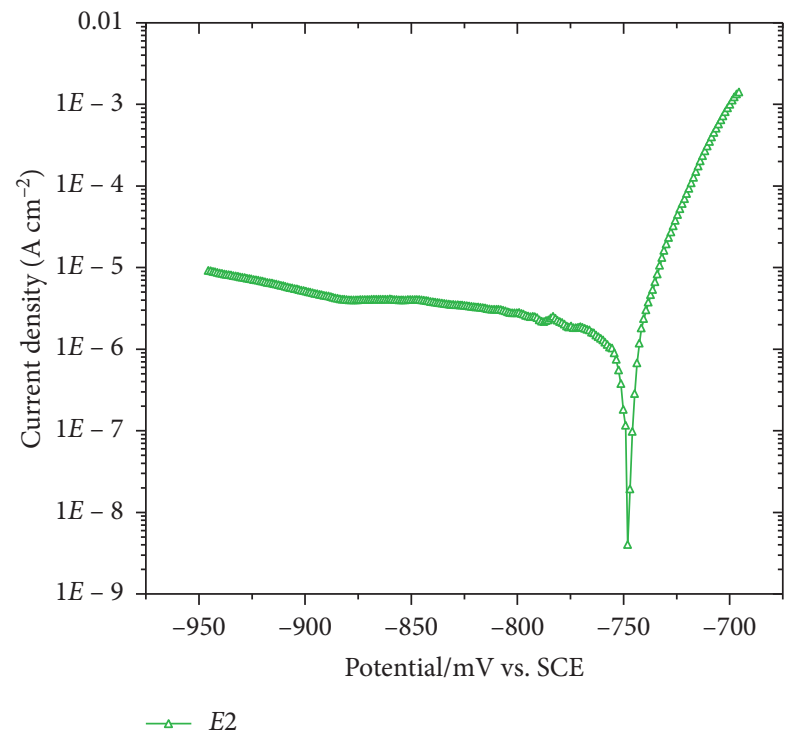

(c)

FigURE 4: LP plots obtained for the different samples tested: (a) general overview; (b) details around the zero-current potential; (c) record of the E2 employed for quantification (see Table 2).

TABLE 3: Effect of ECAP number of passes on the solid-state recycled aluminum alloy 6061 chips after an extrusion temperature of $500^{\circ} \mathrm{C}$.

\begin{tabular}{lcccc}
\hline Description & Hot extruded at $500^{\circ} \mathrm{C}$ & ECAP-2 passes & ECAP-4 passes & ECAP-6 passes \\
\hline Relative density (\%) & 99.6 & 99.9 & 99.9 & 99.9 \\
Microhardness, Vickers & 41 & 94.5 & 103.5 & 110 \\
Ultimate tensile strength (MPa) & 132.4 & 288.5 & 349 & 403 \\
\hline
\end{tabular}

$$
i=i_{\text {corr }}\left(\exp \left(\frac{2.3\left(E-E_{\text {corr }}\right)}{b_{\mathrm{a}}}\right)-\exp \left(\frac{-2.3\left(E-E_{\text {corr }}\right)}{b_{\mathrm{c}}}\right)\right)
$$

where the parameters $i_{\text {corr }}, E_{\text {corr }}, b_{\mathrm{a}}$, and $b_{\mathrm{c}}$ represent the corrosion current, the corrosion potential, the anodic Tafel slope, and the cathodic Tafel slope, respectively.
The data compiled in Table 4 confirm the qualitative observation from Figure 4(a). The corrosion development on all samples proceeds under cathodic control, with Tafel slopes much higher for the cathodic than for the anodic process. The obtained $i_{\text {corr }}$ values reveal the positive effect of the extrusion process on the corrosion rate. The presence of the ECAP is more influencing; nonetheless, the number of passes seems uninfluential on the process. 
TABLE 4: Kinetic parameters obtained from nonlinear fitting of the data presented in Figure 4(a) to equation (1).

\begin{tabular}{lcccc}
\hline Sample & $\begin{array}{c}E_{\text {corr }} \\
\mathrm{mV} \text { vs. SCE }\end{array}$ & $\begin{array}{c}i_{\text {corr }} \\
\mu \mathrm{A} \cdot \mathrm{cm}^{-2}\end{array}$ & $\begin{array}{c}b_{\mathrm{a}} \\
\mathrm{mV} / \text { decade }\end{array}$ & $\begin{array}{c}b_{\mathrm{c}} \\
\mathrm{mV} / \text { decade }\end{array}$ \\
\hline E0 & -734 & 5 & 12 & 432 \\
$E 1$ & -742 & 2.2 & 12 & 374 \\
$E 2$ & -753 & 1.6 & 11 & 363 \\
E3 & -753 & 2.3 & 13 & 171 \\
$E 4$ & -740 & 1.5 & 16 & 256 \\
\hline
\end{tabular}

3.2.2. EIS Results. EIS measurements were performed after about 60 minutes of stabilisation of the electrodes in the test solution. During this time, the electrode potential (open circuit potential, OCP) evolves from initial values of about -1.3 to $-1.2 \mathrm{~V}$ to a final steady state around -0.8 to $-0.75 \mathrm{~V}$. This excursion along the cathodic branches presented in Figure 4(a) is due to the passivation of the aluminum alloy, i.e., the building up of an oxohydroxide layer whose characteristics will depend on the structure and chemical composition of the substrate. The coverage of the metallic substrate makes the corrosion rate to slow down with time, which explains the evolution of the recorded OCP, presented in Figure 5. The rapid variation during the first $20^{\prime}$ of immersion is followed by a lower slope period which, in turn, becomes noisier, typical of the increasing influence of the pitting and repassivation events.

Thus, EIS measurements are expected to gather data on the charge transfer resistance associated with not only the corrosion process but also to the series combination of the two capacitances present at the metal-electrolyte interface: the double layer capacitance and that associated with the aluminum oxohydroxide layer produced during the stabilisation period. Under this concept, the interface is considered as a parallel association of the charge transmission resistance with the interfacial capacitance, whose impedance is described as follows:

$$
Z(\omega)=R_{\mathrm{e}}+\frac{R_{1}}{1+\left(j \omega R_{1} C_{1}\right)^{\alpha_{1}}},
$$

where $R_{\mathrm{e}}$ accounts for the electrolyte resistance, $R_{1}$ for the charge transfer resistance at the metal-electrolyte interface, and $C_{1}$ to the interfacial capacitance which, in this case, contains the contribution of the double layer $\left(C_{\mathrm{dl}}\right)$ and that of the oxide layer $\left(C_{\mathrm{ox}}\right)$ developing on the metal substrate, arranged in series, according to equation (3). $\alpha_{1}$ parameter in equation (2) accounts for a Cole-Cole-type dispersion [25] of the $R_{1} C_{1}$ time constant, which is equivalent to assume a distribution normal to the surface [26]. $\omega=2 \pi \mathrm{f}$ and $j=(-1)^{1 / 2}$.

$$
C_{1}=\frac{C_{\mathrm{ox}} C_{\mathrm{dl}}}{C_{\mathrm{ox}}+C_{\mathrm{dl}}} \text {. }
$$

It is also worth nothing to mention here that the EIS measurements were not performed at the OCP, but about $25 \mathrm{mV}$ cathodic to this potential. This is due to the nonlinearity of the polarization curve at $E_{\text {corr }}$ (Figure 4 ). The imposed $\pm 10 \mathrm{mV}$ AC voltage brings the system in some cases

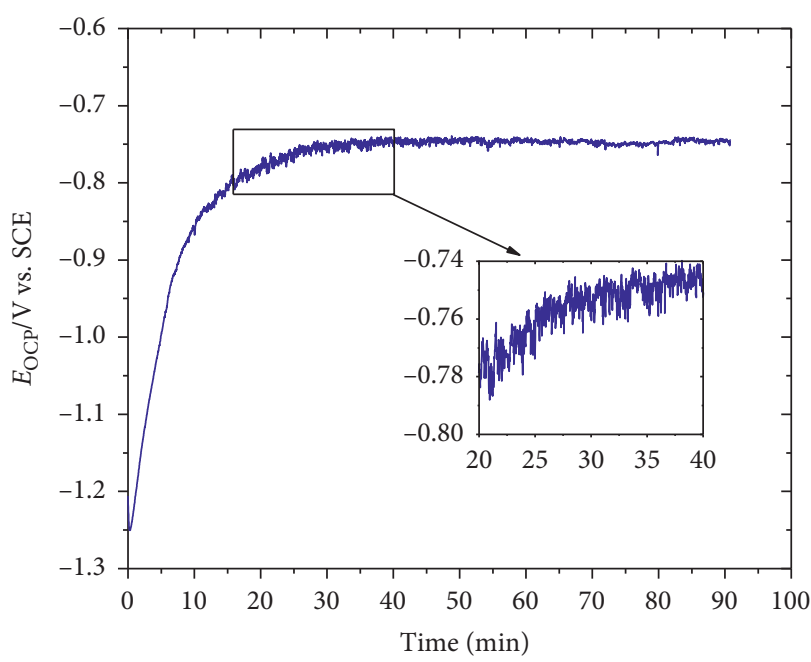

FIgURE 5: Evolution of the OCP of one of the samples, E4, during an expanded stabilisation period.

into the pitting region, which produces highly scattered impedance spectra in the low frequency region. Thus, the small potential displacements chosen allow obtaining reliable impedance spectra with minimal disturbance of the cathodic reaction, as derived from Figure 4. This approach has already been described in the literature [27]. Figure 6 provides an illustration of the impedance spectra obtained. The fitting of the experimental data to the model equation (2) is also represented. The fitting was performed using a simplex method already described [28]. The best fitting parameters are collected in Table 5 where the fitting quality parameter $\chi^{2}$ is also included. Perfect fitting corresponds to $\chi^{2}=1$ because $1 \%$ error in measurements was assumed as default value. Very good agreement is obtained between the experimental and fitted data, as visually shown in Figure 6 and the $\chi^{2}$ values in Table 5 confirm.

According to the arguments presented above, $C_{1}$ shall be regarded as the series combination of $C_{\mathrm{dl}}$ and $C_{\mathrm{ox}}$ following equation (3). Thus, assuming $C_{\mathrm{dl}}$ as constant, any increment in $C_{1}$ values shall be understood with the increase in $C_{\mathrm{ox}}$, i.e., decreasing of the oxide film thickness, according to the following equation:

$$
C_{\mathrm{ox}}=\varepsilon_{\mathrm{ox}} \varepsilon \frac{{ }^{0}}{d},
$$

where consistent to the capacitance of a flat condenser, $\varepsilon_{\mathrm{ox}}$ is the dielectric constant of the oxide, $\varepsilon^{0}$ is the dielectric permittivity of vacuum, and $S$ and $d$ are the geometrical factors surface and thickness, respectively.

The $C_{1}$ values reported in Table 5 suggest that, overall, the film thickness settled on the extruded samples is thinner than that developed on the parent sample. Moreover, $C_{1}$ is inversely proportional to the number of extrusion passes, which suggest the thickening of the passivation layer. This result seems reasonable due to high level energy stocked in the alloy increasing its reactivity, in the sense of self-passivation ability. The kinetic parameter $R_{1}$, inversely proportional to the corrosion rate, reveals the protective 


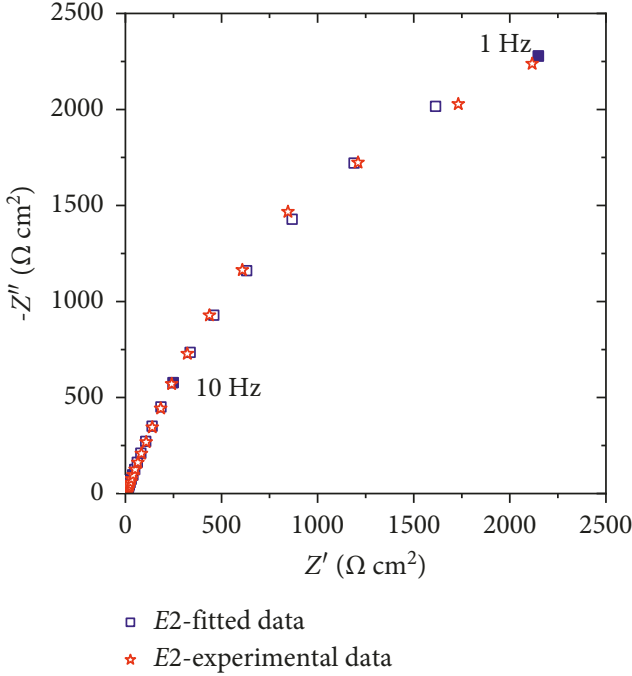

(a)

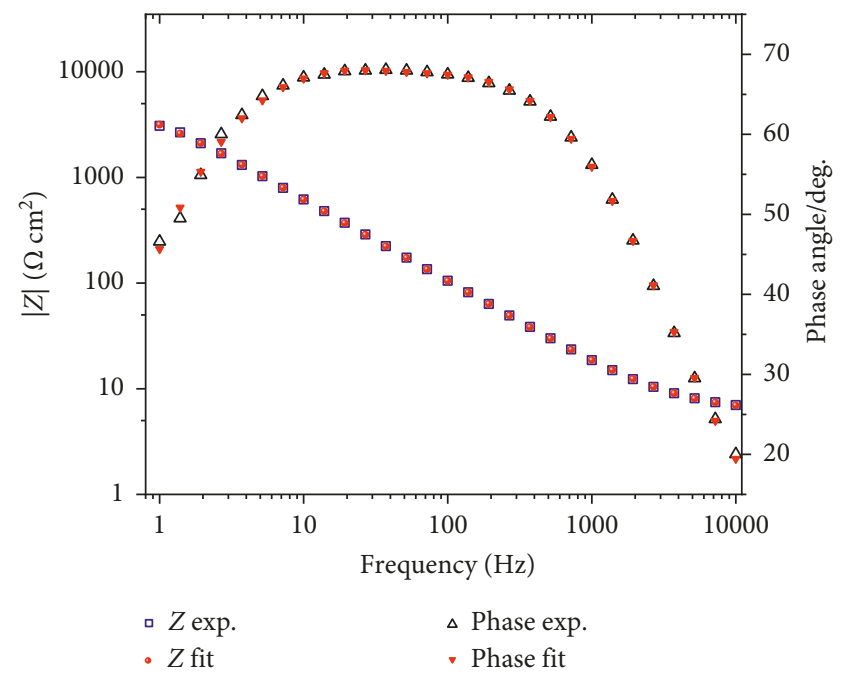

(b)

Figure 6: Nyquist (a) and Bode (b) plots of the interfacial impedance obtained for sample E2. The fitted data using the parameters collected in Table 5 are also included.

TABLE 5: Best fitting parameters obtained from the fitting of the EIS experimental data to a single RC time constant.

\begin{tabular}{lccccc}
\hline Sample & $\begin{array}{c}R_{\mathrm{e}} \\
\Omega \mathrm{cm}^{2}\end{array}$ & $\begin{array}{c}R_{1} \\
\mathrm{k} \Omega \mathrm{cm}^{2}\end{array}$ & $\begin{array}{c}C_{1} \\
\mu \mathrm{F} \cdot \mathrm{cm}^{-2}\end{array}$ & $\alpha_{1}$ & $\chi^{2}$ \\
\hline$E 0$ & 2.94 & 4.916 & 32.71 & 0.8525 & 1.83 \\
$E 1$ & 5.14 & 6.075 & 48.67 & 0.8062 & 1.93 \\
$E 2$ & 5.68 & 6.961 & 44.49 & 0.8006 & 1.43 \\
$E 3$ & 4.69 & 5.643 & 36.39 & 0.8408 & 1.73 \\
$E 4$ & 5.64 & 7.738 & 21.31 & 0.8744 & 1.62 \\
\hline
\end{tabular}

The impedance function is given in equation (2).

capacity of the passive layer especially for the extruded samples. In addition, $R_{1}$ increases from $E 1$ to $E 4$ (the only unexplained exception is $E 3$ ), which is in agreement with the variation observed for $C_{1}$ : the thicker the oxide film, the higher the associated resistance.

\section{Conclusion}

The recycling process using the route of compaction followed by extrusion at elevated temperatures and then ECAP up to six passes was performed. The sample ECAP processed up to six passes exhibited the top-notch ultimate tensile strength and microhardness due to the achieved fine microstructure. The AA6061 alloy experiences spontaneous passivation in $0.5 \mathrm{M} \mathrm{NaCl}$ solution although the corrosion potential achieves the pitting potential, which makes self-passivation kinetics a critical parameter. The self-passivation ability seems to increase after extrusion. The successive ECAP passes lead to increased film thickness and decreased corrosion rate.

\section{Data Availability}

This paper contains all experiments data, and if any researcher requests any extra data, it will be available upon request.

\section{Conflicts of Interest}

The authors declare that there are no conflicts of interest regarding the publication of this paper.

\section{Acknowledgments}

The authors would like to extend their appreciation to the Deanship of Scientific Research at King Saud University for funding this work through the Research Group no. RGP1440-101.

\section{References}

[1] J. Gronostajski and A. Matuszak, "The recycling of metals by plastic deformation: an example of recycling of aluminium and its alloys chips," Journal of Materials Processing Technology, vol. 92-93, no. 35-41, 1999.

[2] C. S. Sharma, T. Nakagawa, and N. Takenaka, "Recent development in the recyclingof machining dwarfs by sintering and powder forging," CIRP Annals-Manufacturing Technology, vol. 26, no. 1, pp. 121-125, 1977.

[3] M. Stern, "Method for treating aluminum or aluminum alloy scrap," US Patent 2391752, 1945.

[4] A. E. Tekkaya, M. Schikorra, D. Becker, D. Biermann, N. Hammer, and K. Pantke, "Hot profile extrusion of AA-6060 aluminum chips," Journal of Materials Processing Technology, vol. 209, no. 7, pp. 3343-3350, 2009.

[5] M. Haase, N. Ben Khalifa, A. E. Tekkaya, and W. Z. Misiolek, "Improving mechanical properties of chip-based aluminum extrudates by integrated extrusion and equal channel angular pressing (iECAP)," Materials Science and Engineering: A, vol. 539, pp. 194-204, 2012.

[6] A. I. Selmy, M. I. Abd El Aal, A. M. El-Gohry, and M. A. Taha, "Solid-state recycling of aluminum alloy (AA-6061) chips via hot extrusion followed by equal channel angular pressing (ECAP)," Egyptian International Journal of Engineering Sciences and Technology, vol. 21, no. 33-42, 2016. 
[7] M. Hu, Z. Ji, X. Chen, and Z. Zhang, "Effect of chip size on mechanical property and microstructure of AZ91D magnesium alloy prepared by solid state recycling," Materials Characterization, vol. 59, no. 4, pp. 385-389, 2008.

[8] S. S. Khamis, M. A. Lajis, and R. A. O. Albert, "A sustainable direct recycling of aluminum chip (AA6061) in hot press forging employing response surface methodology," Procedia CIRP, vol. 26, pp. 477-481, 2015.

[9] B. L. Chan and M. A. Lajis, "Recycling of aluminum 6061 Chip through cold compression," International Journal of Engineering \& Technology, vol. 15, no. 4, pp. 43-47, 2015.

[10] J. R. Duflou, A. E. Tekkaya, M. Haase et al., "Environmental assessment of solid state recycling routes for aluminium alloys: can solid state processes significantly reduce the environmental impact of aluminium recycling?," CIRP Annals, vol. 64, no. 1, pp. 37-40, 2015.

[11] M. I. Abed El Aal, M. A. T. Abbas, A. I. Selmy, A. M. El-Gohry, and H. S. Kim, "Solid state recycling of aluminum AA6061 alloy chips by hot extrusion," Materials Research Express, vol. 6, no. 3, Article ID 036525, 2018.

[12] J. Z. Gronostajski, H. Marciniak, and A. Matuszak, "Production of composites on the base of AlCu 4 alloy chips," Journal of Materials Processing Technology, vol. 60, no. 1-4, pp. 719-722, 1996.

[13] K. Kondoh, T. Luangvaranunt, and T. Aizawa, "Morphologyfree processing of magnesium alloys," Materials Transactions, vol. 42, no. 7, pp. 1254-1257, 2001.

[14] J. B. Fogagnolo, E. M. Ruiz-Navas, M. A. Simón, and M. A. Martinez, "Recycling of aluminium alloy and aluminium matrix composite chips by pressing and hot extrusion," Journal of Materials Processing Technology, vol. 143-144, pp. 792-795, 2003.

[15] J. Gronostajski, H. Marciniak, and A. Matuszak, "New methods of aluminium and aluminium-alloy chips recycling," Journal of Materials Processing Technology, vol. 106, no. 1-3, pp. 34-39, 2000.

[16] V. Güley, A. Güzel, A. Jäger, N. Ben Khalifa, A. E. Tekkaya, and W. Z. Misiolek, "Effect of die design on the welding quality during solid state recycling of AA6060 chips by hot extrusion," Materials Science and Engineering: A, vol. 574, pp. 163-175, 2013.

[17] Y. Chino, T. Hoshika, J.-S. Lee, and M. Mabuchi, "Mechanical properties of AZ31 Mg alloy recycled by severe deformation," Journal of Materials Research, vol. 21, no. 3, pp. 754-760, 2006.

[18] T. Aida, N. Takatsuji, K. Matsuki, S. Kamado, and Y. Kojima, "Homogeneous consolidation process by ECAP for AZ31 cutting chips," Journal of Japan Institute of Light Metals, vol. 54, no. 11, pp. 532-537, 2004.

[19] T. Takahashj, Y. Kume, M. Kobashi, and N. Kanetake, "Solid state recycling of aluminum machined chip wastes by compressive torsion processing," Journal of Japan Institute of Light Metals, vol. 59, no. 7, pp. 354-358, 2009.

[20] T. Peng, Q. D. Wang, and J. B. Lin, "Microstructure and mechanical properties of Mg-10Gd-2Y-0.5Zr alloy recycled by cyclic extrusion compression," Materials Science and Engineering: $A$, vol. 516, no. 1-2, pp. 23-30, 2009.

[21] Q. Shi, Recycling of titanium alloys from machining chips using equal channel angular pressing, Ph.D. thesis, Loughborough University, Loughborough, UK, 2015, https:// dspace.lboro.ac.uk/2134/19515.

[22] D. T. McDonald, E. W. Lui, S. Palanisamy, M. S. Dargusch, and K. Xia, "Achieving superior strength and ductility in Ti$6 \mathrm{Al}-4 \mathrm{~V}$ recycled from machining chips by equal channel angular pressing," Metallurgical and Materials Transactions A, vol. 45, no. 9, pp. 4089-4102, 2014.

[23] M. Mabuchi, K. Kubota, and K. Higashi, "New recycling process by extrusion for machined chips of AZ91 magnesium and mechanical properties of extruded bars," Materials Transactions JIM, vol. 36, no. 10, pp. 1249-1254, 1995.

[24] A. I. Selmy, A. M. El-Gohry, M. I. Abd El Aal, and M. A. Taha, "Characteristics of solid state recycling of aluminum alloy (AA6061) chips by hot extrusion," in Proceedings of the International Conference of Engineering Sciences and Applications, vol. 1, pp. 316-323, Aswan, Egypt, 2016.

[25] K. S. Cole and R. H. Cole, "Dispersion and absorption in dielectrics I. Alternating current characteristics," The Journal of Chemical Physics, vol. 9, no. 4, pp. 341-351, 1941.

[26] M. E. Orazem, I. Frateur, B. Tribollet et al., "Dielectric properties of materials showing constant-phase-element (CPE) impedance response," Journal of The Electrochemical Society, vol. 160, no. 6, pp. C215-C225, 2013.

[27] F. Mansfeld and J. C. S. Fernandes, "Impedance spectra for aluminum 7075 during the early stages of immersion in sodium chloride," Corrosion Science, vol. 34, no. 12, pp. 2105-2108, 1993.

[28] C. M. Abreu, M. Izquierdo, M. Keddam, X. R. Nóvoa, and H. Takenouti, "Electrochemical behaviour of zinc-rich epoxy paints in 3\% $\mathrm{NaCl}$ solution," Electrochimica Acta, vol. 41, no. 15 , pp. 2405-2415, 1996. 

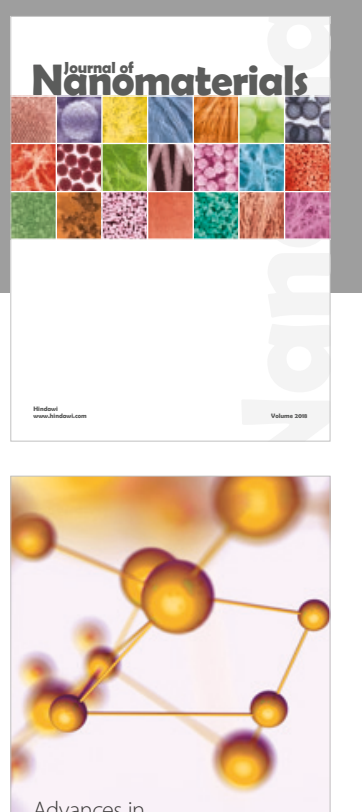

Physical Chemistry
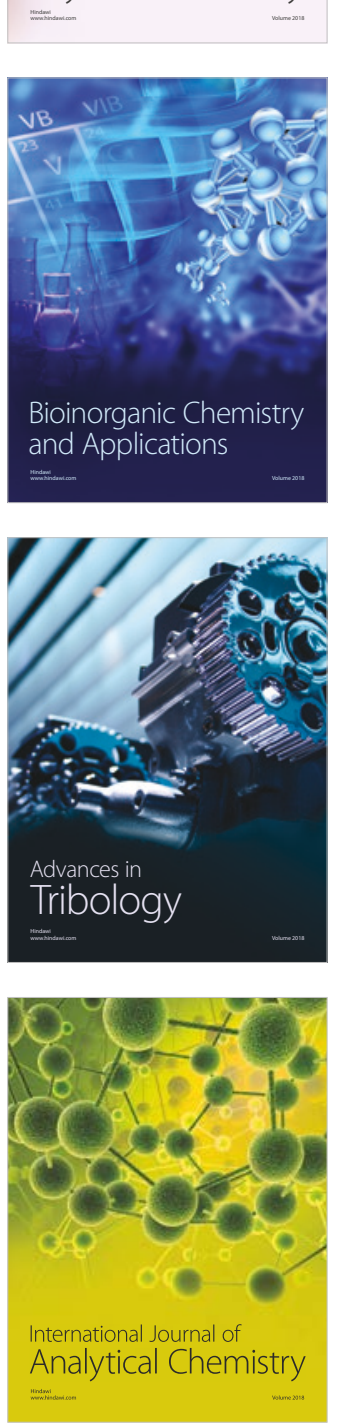

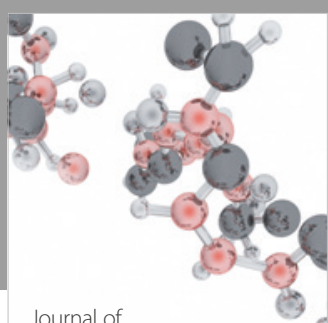

Analytical Methods

in Chemistry

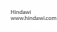

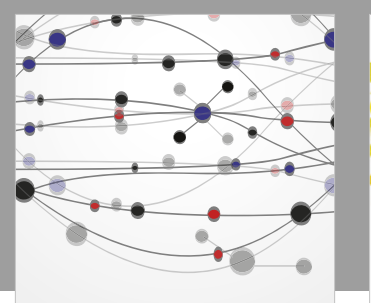

The Scientific World Journal

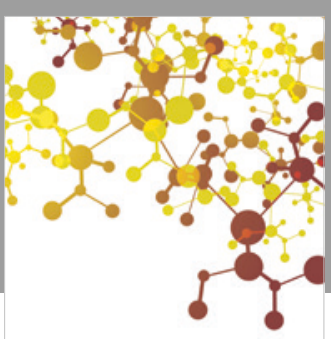

Journal of

Applied Chemistry
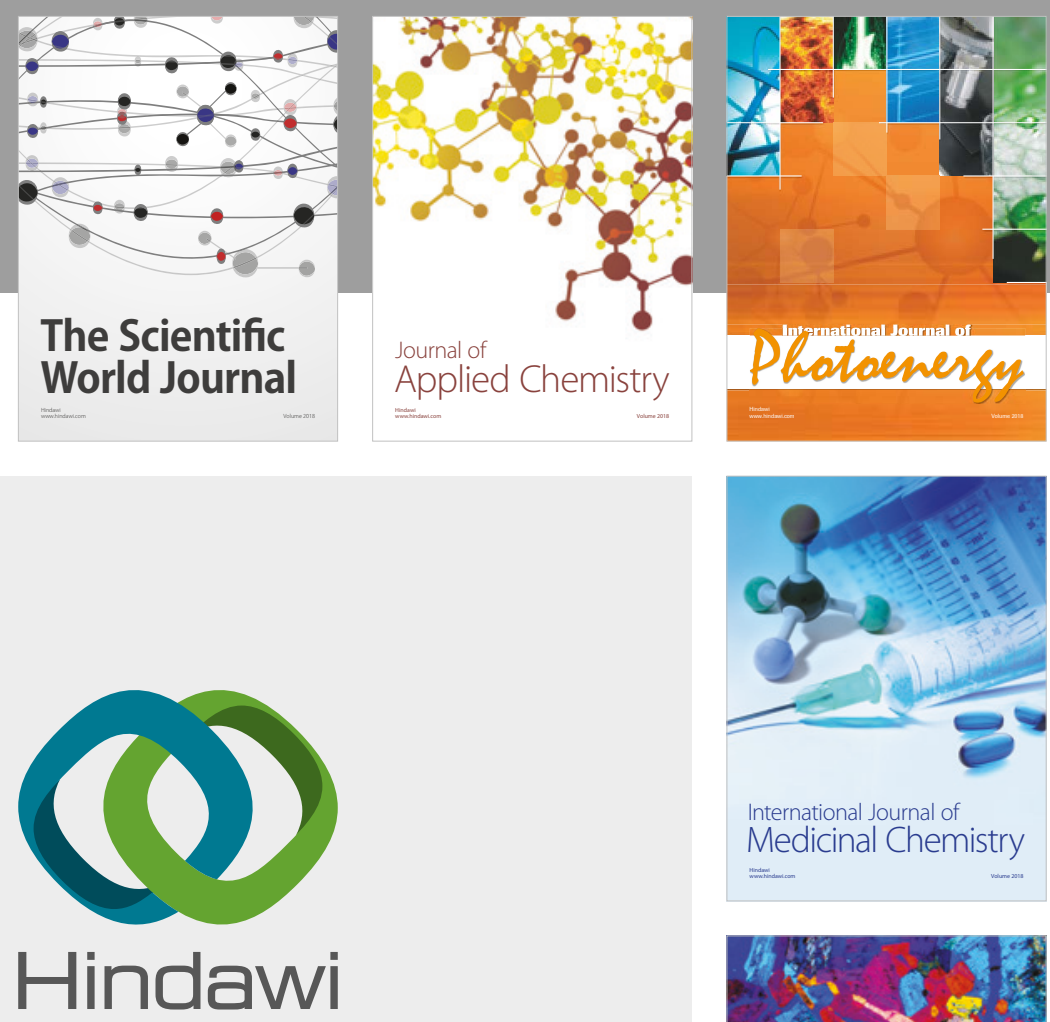

Submit your manuscripts at

www.hindawi.com
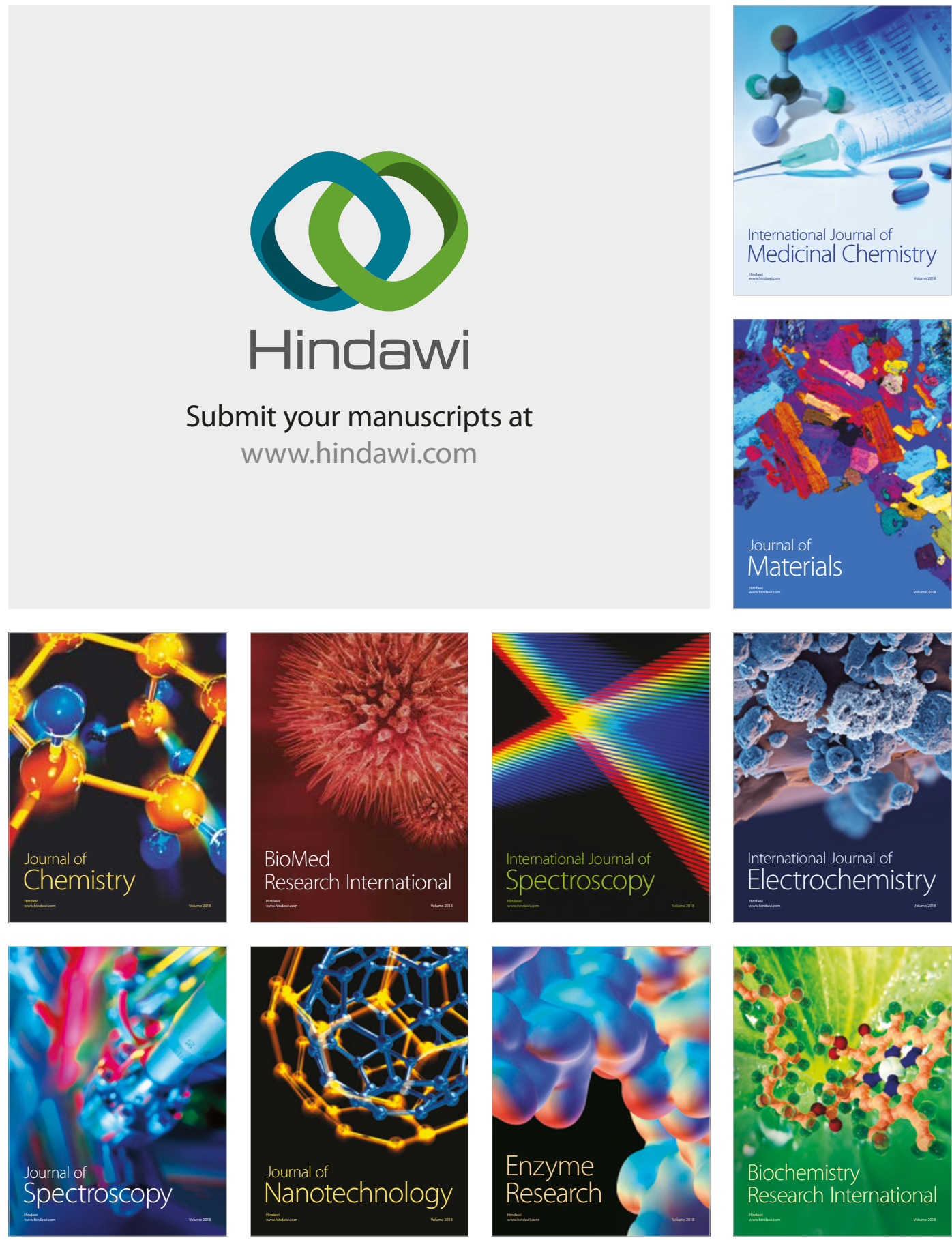
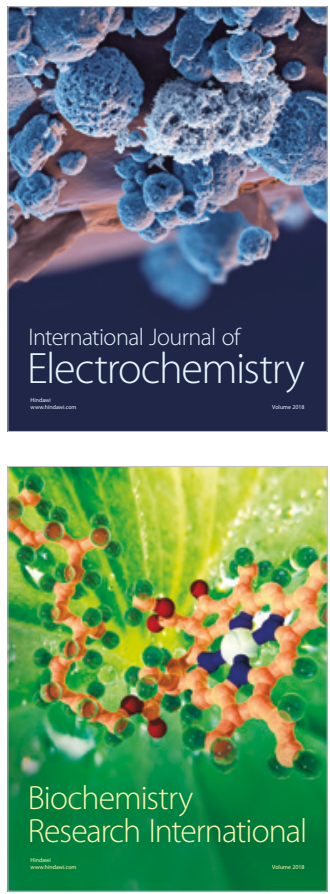